Relato de Experiência

\title{
Terapia ocupacional em uma clínica pediátrica cardiológica durante a pandemia de COVID-19: relato da experiência de uma residente
}

\section{Occupational therapy in a pediatric cardiological clinic during the COVID-19 pandemic: experience report of a resident}

Jéssica Tainara de Macêdo Maia ${ }^{a}$ (D), Débora Ribeiro da Silva Campos Folha ${ }^{a}$ (D), Marly Lobato Maciel ${ }^{a}$ (D), Karla Maria Siqueira Coelho Aita ${ }^{a}$ (D),

Victor Augusto Cavaleiro Corrêa ${ }^{b}$ iD

${ }^{a}$ Universidade do Estado do Pará - UEPA, Belém, PA, Brasil.

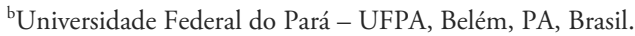

Como citar: Maia, J. T. M., Folha, D. R. S. C., Maciel, M. L., Aita, K. M. S. C., \& Corrêa, V. A. C. (2022). Terapia ocupacional em uma clínica pediátrica cardiológica durante a pandemia de COVID-19: relato da experiência de uma residente. Cadernos Brasileiros de Terapia Ocupacional, 30, e2953.

https://doi.org/10.1590/2526-8910.ctoRE22372953

\begin{abstract}
$\underline{\text { Resumo }}$
O tratamento hospitalar das crianças com cardiopatias produz cerceamento das suas atividades rotineiras como banho, alimentaçãa, escolarização e ludicidade; tal cerceamento se agravou durante a pandemia da COVID-19. Os protocolos de segurança do paciente e de biossegurança hospitalares que objetivam melhoria da qualidade das açôes do cuidado e controle de infecçấo tendem a gerar uma realidade de anonimato, despersonalizaçáo, o que pode exacerbar a presença do temor relativo à dor e à ameaça de morte nos usuários e seus familiares. Os ambientes deste contexto que simbolizavam cuidados essenciais à vida agora passam a ser compreendidos, por parte da população, como o local de maior possibilidade de infecção pelo novo coronavírus. Este conjunto de fatores pode afetar a vida da criança cardiopata, diante da urgência da terapêutica hospitalar, influenciando negativamente na aceitação das intervençôes realizadas neste contexto. Este artigo descreve a vivência sobre a atuação de uma residente de terapia ocupacional no programa em Atenção à Saúde Cardiovascular no contexto hospitalar durante a pandemia COVID-19, sobretudo no ano de 2020, em uma enfermaria pediátrica cardiológica. Trata-se de um estudo de caráter descritivo e cunho qualitativo do tipo relato de experiência profissional. Foi observado que a assistência e o cuidado às crianças e acompanhantes se tornaram restritos aos indivíduos que compartilhavam do mesmo ambiente de enfermaria e com os integrantes da equipe
\end{abstract}


durante as intervençôes. Diante disso, o terapeuta ocupacional se apresentou como o profissional habilitado para identificar rupturas no cotidiano, refletir e intervir em novas formas de atender às demandas ocupacionais e desenvolver recursos e adaptaçôes que correspondessem às necessidades de cada usuário.

Palavras-chave: Cardiopatias Congênitas, Criança Hospitalizada, Formação Profissional, Terapia Ocupacional, Pandemias, COVID-19.

\begin{abstract}
$\underline{\text { Abstract }}$
Hospital treatment of children with congenital heart disease during the SARSCoV-2 pandemic restricts their daily activities such as bathing, eating, studying, and leisure. The protocols of patient safety and hospital biosafety that aim to improve the care quality actions and infection control tend to generate a reality of anonymity, depersonalization, which exacerbates the presence of fear related to pain and the threat of death in patients and their families. In this context, the environments that symbolized essential care for life now come to be understood by the population, as a place of the great possibility of infection by the new coronavirus. This set of factors can affect the lives of children with heart disease, given the urgency of hospital therapy, negatively influencing the acceptance of interventions performed in this context. To reflect on these aspects, this study describes the professional experiences that occurred during the COVID-19 pandemic in 2020 provided by a Cardiovascular Health Care Residency program. It is a descriptive and qualitative study of professional experience reports. In this, it was observed that the interaction of children and companions became restricted to individuals who shared the same ward environment and with the team members during the interventions. Because of this, the occupational therapist is the qualified professional to identify disruptions in daily life, reflect and intervene in new ways to meet occupational demands, develop resources and adaptations that corresponded to the needs of each patient.
\end{abstract}

Keywords: Heart Defects, Congenital, Child Hospitalized, Professional Training, Occupational Therapy, Pandemics, COVID-19.

\title{
Introduçáo
}

Os cuidados para a manutenção da qualidade de vida com criança cardiopata evoluíram ao longo dos últimos 60 anos. Isso proporcionou que, mesmo nos casos mais complexos, seja possível um melhor prognóstico de vida. Desta forma, as condutas terapêuticas têm visado o cuidado integral para a evolução em longo prazo do indivíduo (Aita \& Souza, 2016).

No rol de possibilidades de intervençóes profissionais, no que se refere ao cuidado integral do público abordado, sobretudo no contexto hospitalar, incluem-se os profissionais de terapia ocupacional, cuja intervenção possui o intuito de favorecer o desenvolvimento neuropsicomotor adequado da criança internada, sobretudo por meio da ocupação do brincar e das Atividades de Vida Diárias (AVD’s) (Amaral et al., 2019).

A hospitalização em diferentes faixas etárias pode gerar ansiedade e perda do controle sobre a vida de forma abrupta, resultando em realidade de anonimato e despersonalização. 
Entretanto, o ambiente hospitalar também propicia outras possibilidades de cuidados, no qual a criança e família podem ter maior conhecimento sobre o processo saúde-doença, funcionamento do corpo, favorecimento do desenvolvimento da criança, manejo de dor e sintomas (Menezes \& Moré, 2019; Marcolino et al., 2017).

Durante a pandemia de COVID-19, vivenciar uma internação se tornou algo mais complexo. O contexto hospitalar que simbolizava ambiente de cuidados essenciais à vida agora é compreendido por parte da população como local de maior possibilidade de infecção pelo novo Coronavírus (SARS-CoV-2) (Silva et al., 2020). O que se conhece é que a transmissão do SARS-CoV-2 acontece através de gotículas de saliva da pessoa contaminada e contato com mucosas do indivíduo náo infectado, principalmente em locais fechados e com pouca ventilação, como os hospitais, que podem ser ambientes que facilitam essa transmissibilidade (Medeiros, 2020).

Perante essa realidade do medo por contaminação pelo novo vírus no contexto hospitalar, Falcão et al. (2020) destacam que houve uma diminuição da busca por atendimento em emergência cardiológica em um hospital de Fortaleza-CE, que pode ser resultado da dificuldade de reconhecer sintomas de emergência cardiológica, pouco acesso à assistência desta especialidade, somado ao receio da infecção pelo COVID-19, gerando adiamento da procura por atendimento dos serviços de saúde.

Todavia, não apenas a população em geral tem sido acometida pelas mudanças postas pela pandemia da COVID-19, mas também os profissionais de saúde no ambiente de trabalho, visto que houve aumento da exposição a casos de óbitos em larga escala, recomendaçôes de não interagirem uns com os outros de maneira fisicamente próxima, alto risco de infecção pelo vírus, tempo maior para paramentação e desparamentação dos equipamentos individuais de proteção. Esses fatores podem desencadear ou aumentar sintomas de ansiedade, depressão e estresse (Zhang et al., 2020; Bao et al., 2020).

Neste sentido, este artigo pretende descrever a vivência de uma residente de terapia ocupacional no programa em Atenção à Saúde Cardiovascular no contexto hospitalar, em enfermaria pediátrica cardiológica durante período pandêmico da COVID -19, no ano de 2020 .

\section{Delineando o Percurso Metodológico}

Este estudo possui um caráter descritivo, de cunho qualitativo, do tipo relato de experiência profissional, com finalidade de descrever as vivências profissionais obtidas durante a pandemia de COVID-19 no ano de 2020 ofertadas por um programa de Residência em Atenção à Saúde Cardiovascular.

Dentre os variados cenários de prática disponibilizados pelo programa de residência, optou-se por delimitar a análise ao vivenciado exclusivamente nos ambientes da cardiologia pediátrica de um hospital público de referência na região amazônica, dada a sua relevância para a formação profissional e a oferta de cuidados presentes na singularidade destes usuários do serviço de terapia ocupacional acometidos por cardiopatias congênitas e com COVID19, com separação de enfermarias de acordo com classificação de confirmadas, em processo de confirmação e não-confirmada com COVID-19 .

As experiências na enfermaria pediátrica eram registradas em diário de campo e as reflexôes apontadas encontraram suporte teórico em revisão bibliográfica com publicaçôes científicas no idioma português nos últimos 5 anos, usando as mesmas palavras-chave em 
todas as bases de dados no idioma português: Terapia Ocupacional, Pandemia, Cardiopatias Congênitas e SARS-CoV-2. A busca foi realizada nas bases de dados da Biblioteca Virtual de Saúde (BVS) e Periódicos CAPES e na Revista Interinstitucional Brasileira de Terapia Ocupacional (REVISBRATO). A escolha ocorreu por serem as plataformas que apresentaram resultados para a busca quando consultadas.

\section{Compreendendo o usuário e o cenário da prática}

O programa de residência que possibilitou a experiência pessoal por hora aqui relatada tem como cenário de prática um hospital de referência especializada na atenção à saúde cardiovascular. Recebe usuários advindos da região metropolitana de Belém, assim como dos 144 municípios do Estado do Pará. Esses, em sua grande maioria, são de realidade rural ou ribeirinha, com base econômica familiar na agricultura e/ou pesca. A faixa etária dos usuários internados na clínica pediátrica é de crianças entre 1 mês de vida a 12 anos. São portadores de diferentes Cardiopatias Congênitas (CC), admitidos para procedimentos eletivos ou de urgência, que permanecem internados em média por dois meses, tempo que receberão medicaçóes, inúmeros procedimentos diagnósticos e terapêuticos (Fundação Pública Hospital de Clínicas Gaspar Vianna, 2021). O processo de hospitalização por si próprio é carregado de diversos estressores relacionados a esse ambiente. Somou-se a isso a intensificação das medidas de biossegurança da COVID-19 no contexto hospitalar, elemento que se inscreveu e potencializou de forma negativa as restriçóes durante a realizaçáo das Atividades de Vida Diária (AVD) e Atividades Instrumentais da Vida Diária (AIVD), exacerbou os aspectos emocionais e comportamentais anteriormente citados, além de que intensificou nas crianças e seus familiares o medo de morte, fazendo-os, por vezes, deixar a gravidade da cardiopatia em segundo plano.

\section{Questóes sobre Cotidiano Infantil no Hospital, Terapia Ocupacional e Pandemia}

\section{Dimensóes afetadas pela pandemia}

Segundo Andrade \& Pacheco (2016), a criança procedente dos 144 municípios do Pará habitualmente está inserida no cotidiano da interação direta com o meio ambiente, com o uso de brinquedos feitos da matéria prima da localidade, da interaçáo com grupo social, banho de rio e o brincar em ambientes livres. Desta forma, ao compreender a cultura desta populaçáo, é possível acessar as dimensóes ocupacionais, padróes e significados que cada ocupação possui (Pereira et al., 2018).

Esta realidade é confrontada frente às características comuns da cardiopatia congênita, que geram diversas restriçóes, em sua maioria motoras, devido aos sinais clínicos de taquicardia, dispneia, cansaço e crise de hipóxia. Esses sinais e sintomas podem ocasionar mudanças na rotina, cuidados, medicaçôes e longas internaçóes (Mari, 2015).

Kudo et al. (2018) afirmam que a doença crônica na infância é acompanhada pelas inúmeras ingestóes de medicamento, restriçóes ocupacionais e de funcionalidade, modificaçóes do cotidiano, astenia e a hospitalizaçáo propiciadora de afastamento social, 
medo, exames e estímulos dolorosos, com humor alterado e reativos à presença do profissional de saúde identificado pelo jaleco branco.

Somado a estas condições, é necessário destacar as mudanças ocorridas no cenário da enfermaria cardiopediátrica. No período anterior à pandemia, o setor de internação contava com uma área física composta por 20 leitos e um isolamento para tratamento clínico e/ou cirúrgico cardiológico. As enfermarias ofertavam ambiente climatizado, de 2 a 3 leitos, poltronas individuais para acompanhantes e toalete. Pacientes e acompanhantes tinham livre acesso à área de convivência, com televisão e cadeiras. Dispunha de Sala de Palestras, na qual ocorriam grupos de terapia ocupacional pela manhã e também a Classe hospitalar para continuidade do ensino durante internação, com aulas à tarde para pacientes em idade escolar, direito que é garantido através da Res. No 41/95 (Brasil, 1995). Havia também uma brinquedoteca hospitalar com diversos recursos e materiais disponíveis no horário de oito e meia até às dezessete horas; tal é preconizada pela lei $\mathrm{n}^{\circ} 11,104 / 05$ e portaria $\mathrm{n}^{\circ} 2,261 / \mathrm{GM}$ de 2005 como obrigatórias nas instituiçóes de internação pediátricas, sendo espaço de ludicidade, composta por jogos e brinquedos educativos, visando estimular a criança e acompanhante a brincarem, favorecendo o vínculo, afeto entre si e com seu meio (Brasil, 2005a; Brasil, 2005b). E era ofertada uma vez por mês uma sessão de cinema para crianças e acompanhantes no auditório da Instituição.

Neste cenário de enfermaria, nas intervençóes de terapia ocupacional, poderiam ser utilizadas a brinquedoteca ou Sala de Palestras, sem restriçóes de número de participantes, assim como, individualmente, no leito ou na área de convivência. Tinhase uma ampla possibilidade de recursos, como: quebra cabeça, jogo da memória, recursos de corte e colagem, livros, brinquedos de plástico que remetiam a utensílios de cozinha, bonecas, boliche, bola, entre outros. Estes visavam favorecer habilidades individuais, ludicidade, interação social, vigilância e estimulaçáo do Desenvolvimento Neuropsicomotor (DNPM) no contexto hospitalar.

Observou-se que, durantes as intervenções na internação pediátrica, os objetivos foram frequentemente a promoção à saúde, estimular a independência, participação social e ressignificação do dia a dia hospitalar. Ao propor uma intervenção, a terapeuta ocupacional necessita considerar a história de vida, a cultura, os valores, as preferências e os potenciais adaptados ao contexto hospitalar, assim como suas limitações físicas e restriçóes clínicas do paciente, em intervençóes individuais e/ou grupais, desempenhadas no leito, brinquedotecas, entre outros ambientes (Kudo et al., 2018).

Neste período pandêmico, foi necessário readequar o ambiente da pediatria, no qual duas enfermarias passaram a ser utilizadas como Unidades de Terapias Intensivas (UTI's) pediátrica. Essa distribuição gerou redução do número de leitos para admissão no setor. Tais modificaçóes resultaram em 7 leitos disponíveis para crianças/adolescentes da clínica de cardiologia acometidos por COVID-19 e 3 leitos para crianças da clínica de cardiologia cujo vírus não foi detectado. Houve ainda a necessidade de lançar mão de uma enfermaria transformando-a em posto de enfermagem exclusivo para profissionais que atendiam a enfermarias de COVID-19. Devido a este novo cenário, todas as crianças internadas e seus acompanhantes ficaram restritos, não sendo permitida a saída das enfermarias, visando à prevenção da proliferação do vírus entre pacientes e acompanhantes. Além disso, a Comissão de Controle de Infecção Hospitalar (CCIH) determinou o fechamento da brinquedoteca, a interrupção das atividades escolares da 
classe hospitalar, a suspensão dos grupos de terapia ocupacional com familiares e as atividades de cinema.

Portanto, a interação entre as crianças e os acompanhantes se tornou restrita aos indivíduos que compartilhavam da mesma enfermaria e com os integrantes da equipe durante as intervençóes. A realidade de outrora na qual crianças brincavam livremente em seus lares, interagiam com seu meio e seus familiares. A partir de entáo, tornou-se particularmente distante no ambiente de cardiologia e da infecção por COVID -19, o que impôs para estes usuários adultos e crianças um isolamento dentro do confinamento hospitalar. Ou seja, essa reconfiguração da área física restringiu a exploração do ambiente, diminuiu o acesso aos estímulos e à ludicidade, elemento naturalmente facilitador do desenvolvimento infantil.

A literatura revela que o afastamento da criança do âmbito familiar, dos seus objetos pessoais, dos amigos e escola presentes no processo de hospitalização tende a provocar uma ruptura no cotidiano do usuário. Neste sentido, haverá a necessidade se adaptar a uma rotina por vezes dissonante da cultura familiar, a pessoas e ambiente novos e ao cotidiano hospitalar (Simonato \& Mitre, 2017; Folha \& Della Barba, 2020).

Somado a isto, o distanciamento social recomendado pelo Ministério da Saúde como medida preventiva da contaminaçáo do novo coronavírus pode gerar estresse e desconforto. Porém, mesmo em isolamento social, é importante se manter engajado em ocupaçóes alternativas e significativas possíveis de serem realizadas neste contexto que favoreçam descobertas de novas habilidades, minimizem o estresse, ansiedade e desconforto (De-Carlo et al., 2020).

A terapia ocupacional é a profissão capacitada para identificar rupturas do cotidiano, refletir e intervir em novas formas de atender às demandas ocupacionais, além de desenvolver recursos e adaptaçôes que correspondam às necessidades de cada usuário neste tempo pandêmico. Assim, é esperado que os profissionais de terapia ocupacional atuem no sentido de garantir o direito e a oportunidade à criança de brincar, visto que esta é sua principal ocupação e também objeto primordial no atendimento de terapia ocupacional com este público, sendo o brincar um espaço em que a criança se identifica como sujeito da açáo, interage com o ambiente, tem trocas na relação interpessoal e aproxima seu cotidiano do contexto hospitalar (Silva et al., 2020).

Este talvez tenha sido o principal desafio de intervençáo, visto que a variedade de recursos lúdicos foi diretamente afetada no contexto hospitalar, limitando ainda mais os materiais a serem utilizados durante os atendimentos, considerados como risco de contaminação e possibilidade de vetores de contágio. Isto requereu mais refinamento no raciocínio clínico para as ocupaçóes humanas, ao pensar a atividade, o ambiente, os recursos, materiais e com a prática baseada na ocupação, atendendo às demandas do usuário, à realidade imposta pelo vírus e à biossegurança.

Para além dos recursos materiais, a relação terapêutica foi diversas vezes impactada negativamente, elemento indispensável para as boas práticas em terapia ocupacional. $\mathrm{O}$ contato físico restrito presente no contexto da COVID-19 passa a ser o foco central do setting, adereçado por diversos equipamentos de proteção individual, que dificultam a expressáo dos afetos na interação produzida e na vinculaçáo que se pretende. A relação terapêutica é influenciada pelo ambiente, contexto e aspectos psicológicos em que está inserida. $\mathrm{O}$ vínculo é estabelecido pela relação dinâmica da experiência interpessoal, da observaçáo do rosto, do contato, pela qualidade da atenção, da presença, do processo de 
identificação que ocorre (que é expressa quando o indivíduo imita expressōes faciais), os gestos e que está sucessível à ligação emocional com o outro (Castro, 2007).

Promover o vínculo terapeuta-paciente com a criança tem ainda sido uma tarefa complexa no contexto da cardiologia adoecida pela COVID-19, no qual o tom de voz, o olhar e a expressão corporal se destacam no processo. Entretanto, quando essa relação é estabelecida, a criança pode se sentir segura para manifestar dúvidas, anseios, preocupaçóes referentes à cirurgia e medo da morte, como também pela possibilidade de infecção por COVID-19 e seus agravos. É devido a isto que, além de promover engajamento em atividades apropriadas para sua faixa etária, que proporcionem possibilidade de independência e estimulem o desenvolvimento, terapeutas ocupacionais buscam também favorecer a expressão de conteúdos como medo, ansiedade, dúvidas, permitindo às crianças a externalização de preocupaçóes e que estas sejam respondidas de forma adequada para idade (Simonato \& Mitre, 2019).

Estes aspectos foram abordados por Silva et al. (2019) ao relatarem que, durante o isolamento da criança, é imprescindível a ação da equipe multiprofissional capacitada para promover a escuta qualificada, auxiliando a mesma e sua família a enfrentarem essa experiência com menor sofrimento e prejuízo possíveis. Assim, o terapeuta ocupacional como profissional atuante no enfrentamento do isolamento de contato possui recursos para favorecer os processos de ressignificação desta experiência e estimular adesão ao tratamento.

\section{Reinventando "fazeres": deles, meus, nossos...}

Enfrentou-se dificuldades ao pensar em recursos que atendessem às demandas do usuário de forma satisfatória neste contexto, visto que os recursos disponíveis para o uso do terapeuta ocupacional eram de materiais na sua maioria porosos, impossibilitando a higienização. Outrossim, as opçóes de recursos permanentes e de alto custo precisaram ser descartadas por não atenderem ao critério de exclusividade para seu uso, tornando-os inacessíveis.

Refletir sobre estas dificuldades enquanto profissional de saúde e a urgência em solucionar os novos desafios do contexto de prática, administrar preocupaçóes e limitaçóes de recursos, por vezes, provocaram incertezas que pareciam ser insuperáveis, gerando muita angústia nesta etapa da formação profissional. Contudo, o desafio estava posto e, nele, a premente necessidade de repensar a terapêutica ocupacional, o nosso fazer, reestruturando a formar de planejar açóes, acolher as demandas dos usuários e familiares, revisitar um conhecido/estranho contexto de prática da formaçáo em serviço, o hospital. Dentre os desafios, esteve presente o convívio com a equipe multiprofissional que, nas variadas categorias que a compunham, no transcorrer dos meses, apresentaram infecção por COVID-19; dentre estes, a residente. Nesta altura, o fortuito se tornou realidade e mostrou mais uma vez, sob nova perspectiva, aquilo que havia captado da vivência com usuários portadores de doenças crônicas, no percurso acadêmico: que a morte faz parte do ciclo natural da vida. Sua presença traz inquietude, sofrimento, curiosidade, transformação e relevo à vida. Certamente, dividir este "lugar" com os usuários despertou reflexóes sobre formas de cuidar da terapia ocupacional as quais ainda náo havia cogitado. Este pensar o exercício profissional coadunou com os que defenderam a atuação nas enfermarias e UTI's, readequando as suas práticas à realidade vivenciada (Silva et al., 2020).

Destaco aqui a contribuição do terapeuta ocupacional no enfrentamento à pandemia. No início de abril, o Governo Federal, por meio da Portaria no 639, dispóe sobre a 
estratégia "O Brasil Conta Comigo - Profissionais da Saúde", que objetivou proporcionar capacitação aos profissionais para o enfrentamento da COVID-19, incluindo a terapia ocupacional nas categorias listadas (Brasil, 2020). Reconhecendo a atuação do terapeuta ocupacional nesse momento, a World Federation of Occupational Therapy (2020) salientou as açóes da profissão atuando junto ao indivíduo, família, comunidade, na adaptaçáo social e do ambiente, assim como no uso das medidas de controle de infecçóes, na manutenção da saúde mental, bem-estar e no engajamento de ocupaçóes.

No contexto descrito neste relato de experiência, emergiu para reflexão a premência por se adaptar às circunstâncias postas, enfrentar e superar as limitaçóes, além de transformar a forma de atuar, em concordância com a ética profissional como indispensável no enfrentamento da pandemia de COVID-19 e das suas repercussóes em todas as dimensôes que envolvem a criança com cardiopatia frente à pandemia.

\section{Repensando materiais de intervenção}

Adequar-se às normas de biossegurança mais restritivas, mas sem deixar de olhar estas crianças enquanto seres ocupacionais que são, analisando os processos de mudança que influenciam na transformação das ocupações infantis, permite a oferta de intervenções centradas na ocupação com vistas à participação da criança na vida da família, nos espaços educacionais, nas atividades da comunidade e demais espaços por ela frequentados, como o ambiente hospitalar (Humphry \& Wakeford, 2006; Mandich \& Rodger, 2006). Essa ponderação entre a adequação às novas normas e o atendimento às demandas ocupacionais expressas pelas crianças e suas famílias se mostrou como um processo intenso, desgastante, oneroso, provocativo.

Para alcançar essas demandas de biossegurança, lançou-se mão de recursos descartáveis, como os desenhos impressos. Esse material disponibilizado pelo hospital mediante solicitação, o qual, ao serem recebidos pelo serviço de terapia ocupacional, era armazenado em sacos plásticos por mais de $72 \mathrm{~h}$ para que fosse garantida a não contaminação pelo SarsCov-2. O material era manuseado com as mãos higienizadas, escolhido conforme às preferências e faixa etária da criança e entregue junto à caixa de lápis de cor, que se tornava de uso exclusivo desta para futuro descarte no momento da alta hospitalar.

Relativo à esta estratégia, Silva et al. (2020) reforçam sobre a importância de que o serviço de terapia ocupacional tenha um acervo com brinquedos e materiais de papelaria, os quais possam ser descartados. Assim, as crianças internadas e infectadas pelo SARS- CoV-2 ou não podem ter acesso a recursos lúdicos. De-Carlo et al. (2020) acrescentam que os cuidados de biossegurança pelo terapeuta ocupacional devem incluir a higienização dos recursos, dos equipamentos utilizados e do ambiente, sendo priorizados materiais que possam ser desinfetados e, quando não for possível, sejam descartados, configurando-se critério essencial durante a atuação no contexto hospitalar, em especial no período pandêmico.

Tendo em vista esses aspectos, recursos lúdicos foram desenvolvidos (Figura 1 e 2), impressos e plastificados, possibilitando a higienização com álcool $70^{\circ}$ antes e após o uso. Investiu-se também em atendimentos com brincadeiras cantadas e em contação de histórias, ambas estratégias objetivando corresponder às necessidades de prevenção de infecçôes, assim como visando promover ludicidade, educação em saúde, estimulação cognitiva, motricidade global, além de favorecer o enfrentamento do isolamento social e estimular a ressignificação do processo de internação. É evidente na literatura 
especializada que o terapeuta ocupacional, ao utilizar atividades lúdicas comuns à infância, favorece a adaptação da rotina e do ambiente, tornando-os menos assustadores para a criança, configurando-se potente abordagem para a intervençáo. Apresenta-se ainda como elemento promotor do desenvolvimento social, emocional e intelectual e do engajamento ocupacional (Vieira \& Cazeiro, 2017; Pelosi et al., 2020).

Deste modo, o terapeuta ocupacional pode desenvolver materiais que auxiliem nas orientaçôes de saúde, minimizem a resistência ao uso dos medicamentos, estimulem adesão ao tratamento e possam garantir o engajamento no brincar, na companhia ou não do terapeuta ocupacional, ajustando dessa forma a sua prática profissional à realidade em que atua (Silva et al., 2020; Fonsêca \& Silva, 2015).

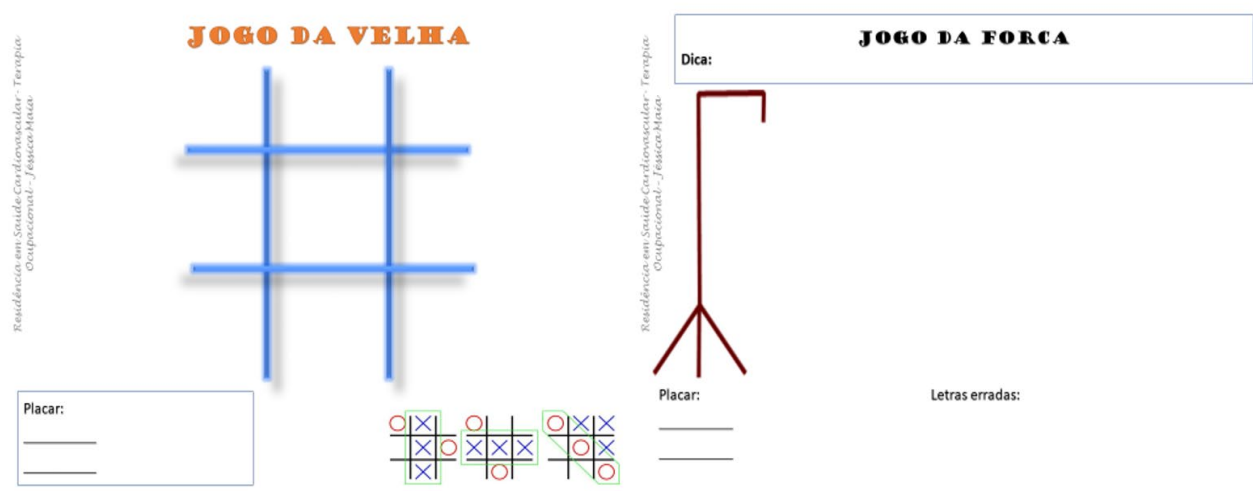

Figura 1. Arquivo do Jogo da velha e de forca para plastificar. Arquivo pessoal (2020).

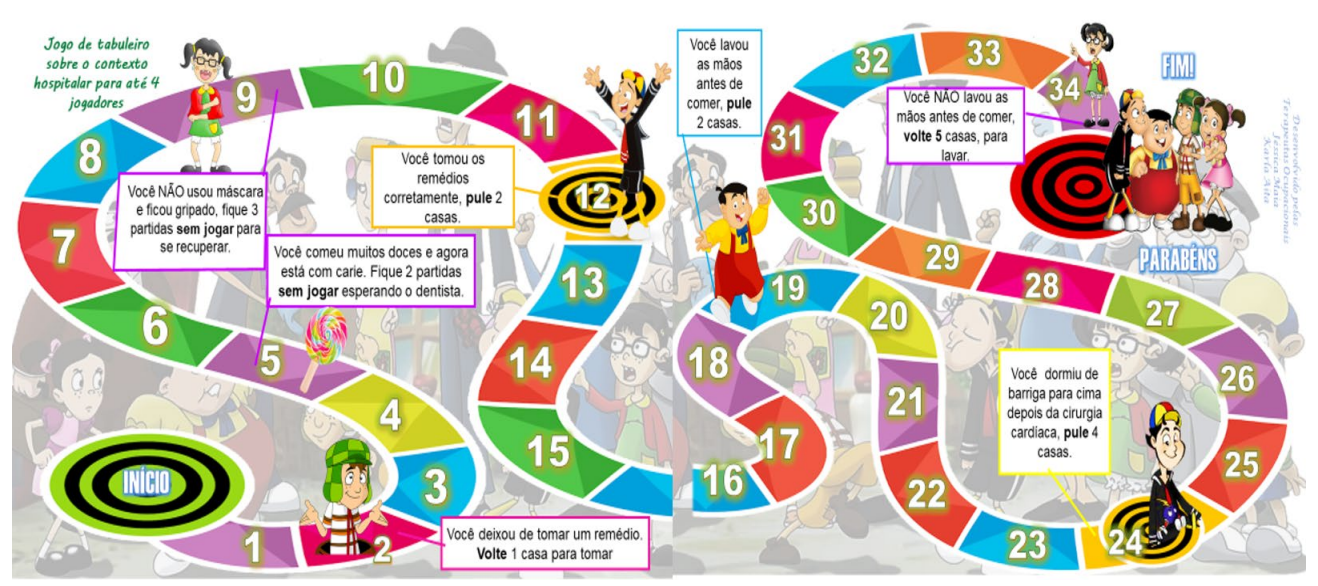

Figura 2. Arquivo do Tabuleiro do Chaves. Arquivo pessoal (2020).

Os recursos lúdicos foram desenvolvidos com objetivo introduzir uma dinâmica interativa que favorecesse a receptibilidade das crianças às intervençôes, a relaçáo terapeuta-paciente e o engajamento no processo terapêutico e nas ocupaçóes infantis realizadas no contexto hospitalar. 


\section{Biossegurança hospitalar, família e terapia ocupacional}

Uma questão importante a ser destacada é quanto à sobrecarga do familiar neste processo, visto que as trocas de acompanhantes, nesse contexto, sofreram mudanças e estiveram limitadas para diminuir o risco de infecção trazidas do meio externo para o ambiente das enfermarias, assim como as visitas foram suspensas, aumentando o tempo de permanência de um mesmo acompanhante no hospital e diminuindo o contato com os demais integrantes da família.

Camelo Júnior (2020) diz que, apesar da importância de reestruturaçóes na rotina hospitalar, algumas açóes se tornaram geradoras de estresse e problemas relacionados à saúde mental, como a suspensão de visitas e restrição de acompanhantes para crianças. Neste período, pais e mães se distanciam de suas funçóes e papeis ocupacionais, devido à necessidade de permanecer no hospital, demandando buscar sua rede de apoio (Souza, 2019).

Do mesmo modo, o cansaço, o desgaste, o esgotamento físico, mental e emocional são recorrentes em acompanhantes de pacientes hospitalizados. E o hospital pode representar lugar de tristeza, solidão, saudade de amigos e familiares (Frizzo \& Corrêa, 2018). A falta do contato mais próximo dos acompanhantes com os demais familiares devido às restriçóes, à estafa física e emocional pelo longo período no hospital e à preocupaçáo com as ocupaçóes deixadas para se dedicar ao cuidar no contexto hospitalar são situaçóes que chamaram atenção nesse contexto, com destaque para as repercussóes ocupacionais.

Em vista disso, este período exigiu um olhar mais delicado às demandas desses familiares devido aos desafios enfrentados por eles amplificados pelas restriçóes recomendadas. Destaca-se que as açóes de educaçáo em saúde, além da ênfase na vigilância do desenvolvimento em que seja valorizado sobretudo as potencialidades e aquisiçóes da criança, tendem a subsidiar de forma positiva intervençóes frente ao COVID-19 e o anseio da alta hospitalar. Contudo, é preciso questionar se a vivência do acompanhante que é profundamente impactado pelo adoecimento do filho(a) resultará em marcas no indivíduo que nem sempre serão visíveis, mas poderão ser percebidas. A fim de ofertar atendimento humanizado e desconstruir os temores que em geral são apresentados por este segmento no contexto hospitalar, deve-se estar aberto a acolher as dúvidas, orientar sobre o fluxo de internação e ofertar escuta terapêutica ocupacional para com os acompanhantes das crianças atendidas (Menezes \& Moré, 2019; Rodrigues et al., 2020).

\section{Consideraçóes Finais}

Ao descrever ocotidiano vivenciado na prática da residência ocorrida na clínica pediátrica cardiológica durante a pandemia de COVID-19, evidenciou-se como a vulnerabilidade e impotência se capitalizaram e atravessaram o raciocínio clínico, a elegibilidade dos recursos materiais, das ocupaçóes, assim como a relação terapêutica com os usuários e a familiares.

Estar internado neste período não apenas ocasionou rupturas ocupacionais, afastamento do cotidiano, da cultura e do contexto familiar, como também reduziu as possibilidades de interação dentro do próprio contexto hospitalar, afunilou as estratégias de enfrentamento da internação e amplificou o sofrimento inerente ao tratamento clínico imposto pela cardiopatia. 
Da mesma forma, estas mudanças impactaram os profissionais de saúde. Atuar enquanto terapeuta ocupacional residente neste período pandêmico por vezes suscitou medos, anseios, inseguranças e dúvidas relacionadas à prática hospitalar e à possibilidade de contaminação. Contudo, estes sentimentos foram superados pela satisfação e realização de intervir nas mudanças e demandas ocupacionais evidenciadas pela clientela infantil internada.

Terapeutas ocupacionais devem e podem promover o engajamento nas ocupaçóes significativas e a adaptação dos ambientes e desenvolver com a equipe multiprofissional, junto às crianças e familiares, estratégias de enfrentamento da hospitalização e da Covid19. A experiência no exercício da terapia ocupacional nesse período possibilitou reavivar a crença na minha, na deles, na nossa capacidade de nos reinventar e superar os desafios.

\section{Referências}

Aita, K. M. S. C., \& Souza, A. M. (2016). Cenas sobre a morte, reveladas pela criança cardiopata, por abrir o coração. Revista do Nufen: Phenomenology and interdisciplinarity, 8(1), 141-162. Recuperado em 07 de setembro de 2019, de http://pepsic.bvsalud.org/pdf/rnufen/v8n1/a10.pdf.

Amaral, I. G. S., Corrêa, V. A. C., \& Aita, K. M. S. C. (2019). Perfil de independência no autocuidado da criança com Síndrome de Down e com cardiopatia congênita. Cadernos Brasileiros de Terapia Ocupacional, 27(3), 555-563. Recuperado em 15 de junho de 2021. https://doi.org/10.4322/25268910.ctoAO1659.

Andrade, S. S., \& Pacheco, T. D. S. C. (2016). Infâncias e crianças ribeirinhas da Amazônia marajoara: linguagens e práticas culturais. Arquivo Brasileiro de Educaçấo, 4(9), 104-116. Recuperado em 05 de janeiro de 2021, de https://doi.org/10.5752/P.2318-7344.2016v4n9p104.

Bao, Y., Sum, Y., Meng, S., Shi, J., \& Lu, L. (2020). 2019-nCoV epidemic: address mental health care to empower society. The Lancet, 395(10224), E37-E38. Recuperado em 02 de agosto de 2020, de http://dx.doi.org/10.1016/s0140-6736(20)30309-3.

Brasil. (1995, 17 de outubro). Resolução n ${ }^{\circ}$ 41, de 13 de outubro de 1995. Aprova na íntegra o texto da Sociedade Brasileira de Pediatria, relativo aos direitos da criança e do adolescente hospitalizado. Conselho Nacional de Direitos da Criança e do Adolescente. Diário Oficial [da] República Federativa do Brasil, Brasília. Recuperado em 21 de julho de 2020, de

https:/www.mpdft.mp.br/portal/pdf/unidades/promotorias/pdij/Legislacao\%20e\%20Jurisprudencia /Res_41_95_Conanda.pdf.

Brasil. (2005a, 22 de março). Lei no 11.104 de 21 de março de 2005. Dispóe sobre a obrigatoriedade de instalação de brinquedotecas nas unidades de saúde que ofereçam atendimento pediátrico em regime de internaçáo. Diário Oficial [da] República Federativa do Brasil, Brasília. Recuperado em 21 de julho de 2020, de https:/www.planalto.gov.br/ccivil_03/_ato2004-2006/2005/lei/l11104.htm.

Brasil. (2005b, 24 de novembro). Portaria No 2.261, de 23 de novembro de 2005. Aprova o

Regulamento que estabelece as diretrizes de instalaçáo e funcionamento das brinquedotecas nas unidades de saúde que ofereçam atendimento pediátrico em regime de internação. Diário Oficial [da] República Federativa do Brasil, Brasília. Recuperado em 21 de julho de 2020, de http://bvsms.saude.gov.br/bvs/saudelegis/gm/2005/prt2261_23_11_2005.html.

Brasil. (2020, 02 de abril). Portaria MS/GM n 639, de 31 de março de 2020. Dispõe sobre a Ação Estratégica "O Brasil conta comigo-profissionais da saúde", voltada à capacitação e ao cadastramento de profissionais da área de saúde, para o enfrentamento à pandemia do coronavírus (COVID19). Diário Oficial [da] República Federativa do Brasil, Brasília. Recuperado em 09 de janeiro de 2021, de https://www.in.gov.br/en/web/dou/-/portaria-n-639-de-31-de-marco-de-2020-250847738.

Camelo Júnior, J. S. (2020). Pandemia de COVID19 e a saúde mental de pacientes, famílias e trabalhadores da saúde: oportunidade de transformação. Revista Qualidade HC, 6(1), 156-165.

Recuperado em 09 de janeiro de 2021, de https://www.hcrp.usp.br/revistaqualidadehc/edicaoselecionada.aspx?Edicao=11. 
Castro, E. D. (2007). Relação terapeuta-paciente. In A. Cavalcanti \& C. Galvão (Eds.), Terapia ocupacional: fundamentação e prática (pp. 28-34). Rio de Janeiro: Guanabara Koogan.

De-Carlo, M. M. R. P., Gomes-Ferraz, C. A., Rezende, G., Buin, L., Moreira, D. J. A., Souza, K. L. D., Sacramento, A. M., Santos, W. A., Mendes, P. V. B., \& Vendrusculo-Fangel, L. M. (2020). Diretrizes para a assistência da terapia ocupacional na pandemia da COVID-19 e perspectivas póspandemia. Revista da Faculdade de Medicina de Ribeirão Preto, 53(3), 332-69. Recuperado em 10 de janeiro de 2021, de https://www.revistas.usp.br/rmrp/article/view/173471.

Falcão, J. L. A. A., Rabelo, D. R. V., Falcão, S. N. R. S., Pereira Neto, J. A., Arnould, F. C. S., Belém, L. S., Sousa, L. S., \& Falcão, B. A. A. (2020). Impacto do isolamento social na pandemia de COVID19 sobre atendimentos de emergência e angioplastias para infarto do miocárdio em hospital cardiológico. Journal of Transcatheter Interventions, 28, eA20200009. Recuperado em 02 agosto de 2020, de http://dx.doi.org/10.31160/jotci202028a20200009.

Folha, D. R. D. S. C., \& Della Barba, P. C. D. S. (2020). Produção de conhecimento sobre terapia ocupacional e ocupaçôes infantis: uma revisão de literatura. Cadernos Brasileiros de Terapia Ocupacional, 28(1), 227-245.

Fonsêca, M. E. D., \& Silva, Â. C. D. (2015). Concepçôes e uso do brincar na prática clínica de terapeutas ocupacionais. Cadernos Brasileiros de Terapia Ocupacional, 23(3), 589-597. http://dx.doi.org/10.4322/01044931.ctoAO0554.

Frizzo, H. C. F., \& Corrêa, V. A. C. (2018). Perdas e luto. In M. M. R. P. De-Carlo \& A. M. Kudo (Eds.), Terapia Ocupacional em contextos hospitalares e cuidados paliativos (pp. 387-398). São Paulo: Editora Payá.

Fundação Pública Hospital de Clínicas Gaspar Vianna - FPHCGV (2021). Serviço de arquivo médico e estatística. Belém. Recuperado em 08 de janeiro de 2021, de http://www.gasparvianna.pa.gov.br/site_novo/wp/hospital/hc-em-numeros.

Humphry, R., \& Wakeford, L. (2006). An occupation-centered discussion of development and implications for practice. The American Journal of Occupational Therapy, 60(3), 258-267. Recuperado em 15 de junho de 2021. https://doi.org/10.5014/ajot.60.3.258.

Kudo, A. M., Barros, P. B. M., \& Joaquim, R. H. V. T. (2018). Terapia ocupacional em enfermaria pediátrica e brinquedoteca hospitalar. In M. M. R. P. De-Carlo \& A. M. Kudo (Eds.), Terapia ocupacional em contextos hospitalares e cuidados paliativos (pp. 127-143). São Paulo: Editora Payá.

Mandich, A., \& Rodger, S. (2006). Doing, being and becoming: their importance for children. In S. Rodger \& J. Ziviani (Eds.), Occupational therapy with children: understanding children's occupations and enabling participation (pp. 115-135). Malden: Blackwell Publishing.

Marcolino, T. Q., Joaquim, R. H. V. T., Bombarda, T. B., \& Reali, A. M. R. (2017). Terapia ocupacional en el hospital: construcciones de sentido en una comunidad de práctica. Revista Chilena de Terapia Occupacional, 17(1), 81-89. Recuperado em 06 de janeiro de 2020, de https://doi.org/10.5354/0719-5346.2017.46391.

Mari, M. A. (2015). Avaliação do desenvolvimento infantil e a influência dos fatores biopsicossociais em crianças com cardiopatia congênita (Monografia). Universidade Federal do Rio Grande do Norte, Natal. Recuperado em 16 de agosto de 2020, de https://repositorio.ufrn.br/jspui/handle/123456789/20148.

Medeiros, E. A. S. (2020). A luta dos profissionais de saúde no enfrentamento da COVID-19. Acta Paulista de Enfermagem, 33, e-EDT20200003. Recuperado em 02 agosto de 2020, de http://dx.doi.org/10.37689/acta-ape/2020edt0003.

Menezes, M., \& Moré, C. (2019). Significaçôes da hospitalização na infância. Curitiba: Editora Appris.

Pelosi, M. B., Ferreira, K. G., \& Nascimento, J. S. (2020). Atividades terapêuticas ocupacionais desenvolvidas com crianças e pré-adolescentes com síndrome de Down. Cadernos Brasileiros de Terapia Ocupacional, 28(2), 511-524. http://dx.doi.org/10.4322/2526-8910.ctoAO1782.

Pereira, L. T., Siqueira, L. S., Correa, V. A. C., Araujo, L. S., \& Folha, O. A. A. C. (2018). Caracterização das ocupaçôes de moradores de uma comunidade ribeirinha na Amazônia brasileira. Revista de Ocupação Humana, 18(2), 5-19. Recuperado em 06 de janeiro de 2020, de https://latinjournal.org/index.php/roh/article/view/232/165. 
Rodrigues, J. I. B., Fernandes, S. M. G. C., \& Marques, G. F. D. S. (2020). Preocupaçóes e necessidades dos pais de crianças hospitalizadas. Saúde e Sociedade, 2(29), e190395. Recuperado em 06 de janeiro de 2020, de https://doi.org/10.1590/S0104-12902020190395.

Silva, J. I. P., Kudo, A. M., Jacob, L. R., \& Galheigo, S. M. (2019). Isolamento hospitalar pediátrico: o olhar da criança. Revista Interinstitucional Brasileira de Terapia Ocupacional, 3(4), 508-525. Recuperado em 05 de janeiro de 2021, de https://doi.org/10.47222/2526-3544.rbto25356.

Silva, M. R., Silva, P. C., Rabelo, H. D., \& Vinhas, B. C. V. (2020). A terapia ocupacional pediátrica brasileira diante da pandemia da COVID- 19: reformulando a prática profissional. Revista Brasileira de Terapia Ocupacional, 4(3), 422-437. Recuperado em 21 de julho de 2020, de https://revistas.ufrj.br/index.php/ribto/article/view/34171/pdf.

Simonato, M. P., \& Mitre, R. M. A. (2017). Sutilezas e tessituras do ambiente hospitalar: o cotidiano de uma enfermaria pediátrica de média e alta complexidade. Cadernos Brasileiros de Terapia Ocupacional, 25(2), 245-254. Recuperado em 09 de janeiro de 2021, de http://dx.doi.org/10.4322/0104-4931.ctoAO0841.

Simonato, M. P., \& Mitre, R. M. A. (2019). A terapia ocupacional e os cuidados paliativos pediátricos. In A. V. Rubio \& J. L. Souza (Eds.), Cuidado Paliativo: pediátrico e perinatal (pp. 119-133). Rio de Janeiro: Atheneu.

Souza, F. D. A. (2019). A intervenção da terapia ocupacional cuidando da qualidade de vida. In A. V. Rúbio \& J. L. Souza (Eds.), Cuidado Paliativo pediátrico e perinatal (pp. 141-152). Rio de Janeiro: Atheneu.

Vieira, S. R., \& Cazeiro, A. P. M. (2017). Análise de jogos e brincadeiras para o contexto hospitalar. Revista Interinstitucional Brasileira de Terapia Ocupacional, 1(2), 127-148. Recuperado em 06 de janeiro de 2020, de https://doi.org/10.47222/2526-3544.rbto4639.

World Federation of Occupational Therapy - WFOT (2020). Declaração Pública: resposta da terapia ocupacional à pandemia COVID-19. Reino Unido. Recuperado em 08 de janeiro de 2021, de https://www.wfot.org/about/public-statement-occupational-therapy-response-to-the-covid-19-pandemic.

Zhang, J., Wu, W., Zhao, X., \& Zhang, W. (2020). Recommended psychological crisis intervention response to the 2019 novel coronavirus pneumonia outbreak in China: a model of west china hospital. Precision Clinical Medicine, 3(1), 3-8. Recuperado em 02 de agosto de 2020, de http://dx.doi.org/10.1093/pcmedi/pbaa006.

\section{Contribuiçáo dos Autores}

Jéssica Tainara de Macêdo Maia: Concepção do texto e organização das fontes. Débora Ribeiro da Silva Campos Folha, Victor Augusto Cavaleiro Corrêa e Marly Lobato Maciel: Análise e orientações. Karla Maria Siqueira Coelho Aita: Orientação, análise e correçôes. Todos os autores aprovaram a versão final do artigo.

\section{Autor para correspondência}

Jéssica Tainara de Macêdo Maia

e-mail: jessicatmmaia@gmail.com

\section{Editora de seçáo}

Profa. Dra. Luzia Iara Pfeifer 